\title{
Chymase inhibition protects diabetic rats from renal lesions
}

\author{
MEI ZHANG ${ }^{1}$, WEN HUANG ${ }^{1}$, JING BAI $^{1}$, XIAODONG NIE $^{1}$ and WEN WANG ${ }^{2}$ \\ ${ }^{1}$ Department of Nephrology, Beijing Tongren Hospital, Capital Medical University, Beijing 100730; \\ ${ }^{2}$ Department of Physiology and Pathophysiology, School of Basic Medical Sciences, \\ Capital Medical University, Beijing 100069, P.R. China
}

Received May 2, 2015; Accepted April 1, 2016

DOI: $10.3892 / \mathrm{mmr} .2016 .5234$

\begin{abstract}
The present study aimed to investigate the effects of a chymase inhibitor on renal injury in diabetic rats. A total of 24 Sprague-Dawley rats were randomly divided into the following groups: The control group $(n=7)$, the diabetes group (DM group; $n=7$ ), and the $\mathrm{DM}+$ chymase inhibitor group (DM + Chy-I group; $n=10)$. Diabetes was induced via an intraperitoneal injection of streptozotocin $(65 \mathrm{mg} / \mathrm{kg})$. Rats in the DM + Chy-I group were administered $1 \mathrm{mg} / \mathrm{kg}$ chymase inhibitor [Suc-Val-Pro-Phe ${ }^{\mathrm{P}}-(\mathrm{OPh})_{2}$ ] daily for 12 weeks by intraperitoneal injection. Subsequently, kidney weight, various biochemical parameters and blood pressure were measured. In addition, the expression levels of fibronectin (FN), type IV collagen (ColIV), transforming growth factor (TGF)- $\beta 1$ and vascular endothelial growth factor (VEGF) were determined by immunohistochemistry and reverse transcription polymerase chain reaction. Compared with in the DM group, the levels of serum cholesterol and urinary albumin/creatinine were decreased in the DM + Chy-I group $(\mathrm{P}<0.05)$. Furthermore, chymase inhibition reduced the overexpression of FN, ColIV, TGF- $\beta 1$ and VEGF $(\mathrm{P}<0.05)$ in the renal tissue of diabetic rats. These results indicated that chymase inhibition may reduce the excretion of urinary albumin and the deposition of extracellular matrix components in the kidney of diabetic rats. These effects may be mediated by altered expression of the VEGF and TGF- $\beta 1$ pathways. In conclusion, chymase inhibition may be considered a potential method for the treatment of renal damage.
\end{abstract}

\section{Introduction}

Nephropathy, which is one of the most common complications of diabetes, is characterized by proteinuria, renal dysfunction,

Correspondence to: Dr Mei Zhang or Professor Wen Huang, Department of Nephrology, Beijing Tongren Hospital, Capital Medical University, 1 Dongjiaominxiang, Dongcheng, Beijing 100730, P.R. China

E-mail: zhangmei67@hotmail.com; zhangm1@trhos.com

E-mail: huangw6@126.com

Key words: chymase inhibitor, diabetic rats, renal injury and end stage renal disease. However, the precise mechanisms underlying the progression of diabetes mellitus-induced renal injury remain unclear. Huang et al (1) reported that the expression of angiotensin-converting enzyme (ACE) was significantly upregulated in tubular epithelial cells and infiltrating mononuclear cells in diabetic kidneys. In addition, diabetic kidneys exhibited significantly increased chymase expression in mesangial cells and vascular smooth muscle cells, and increased chymase deposition was detected in the collagen-rich extracellular matrix (ECM) alongside diffused and nodular glomerulosclerosis, tubulointerstitial fibrosis, and vascular sclerosis (1). In a hamster model of unilateral ureteral obstruction, treatment with a chymase inhibitor significantly reduced angiotensin (Ang) II levels, significantly decreased the mRNA expression levels of $\alpha$-smooth muscle actin, type I collagen and transforming growth factor (TGF)- $\beta 1$ in renal tissue, and appeared to ameliorate tubulointerstitial injury. However, chymase inhibition did not alter systolic blood pressure, or the protein levels of renal ACE and Ang II receptor type 1 (2).

As a chymotrypsin-like serine protease, chymase is synthesized in mast cells, endothelial cells and mesenchymal cells. Chymase is secreted directly into the interstitium, and is responsible for the synthesis of $\leq 80 \%$ of Ang II in the human heart (3). Chymase is inactivated in the blood immediately after release, thus indicating that chymase is only active in local tissues (4). Human and hamster chymases have been reported to activate the conversion of Ang I to Ang II, and contribute toward TGF- $\beta 1$ activation (5), whereas rat chymase activates TGF- $\beta$ but not Ang II (6). In the present study, a rat model was selected to determine the role of chymase in diabetes mellitus-associated renal injury, without the Ang II effects.

Suc-Val-Pro-Phe ${ }^{\mathrm{P}}-(\mathrm{OPh})_{2}$ [also known as $(\mathrm{OPh})_{2}$ ] specifically inhibits chymase without affecting ACE activity, and has a degradation half-life of $20 \mathrm{~h}$ in human plasma (half maximal inhibitory concentration $=2.8 \mathrm{nmol} / \mathrm{l})(7)$. Therefore, $(\mathrm{OPh})_{2}$ may act as a stable and strong chymase inhibitor in vivo (8), and was used in the present study to investigate the role of chymase in diabetic renal injury.

\section{Materials and methods}

Materials. Male Sprague-Dawley rats (180-200 g) were purchased from Beijing Vital River Laboratory Animal 
Technology Co., Ltd. (Beijing, China). The chymase inhibitor $(\mathrm{Oph})_{2}$ was generously provided by Dr. Shinji Takai (Department of Pharmacology, Osaka Medical College, Osaka, Japan). Monoclonal mouse anti-fibronectin (FN; sc-8422), rabbit anti-type IV collagen (ColIV; sc-11360) and mouse anti-TGF- $\beta 1$ (sc-52893) antibodies were purchased from Santa Cruz Biotechnology, Inc. (Dallas, TX, USA). The horseradish peroxidase (HRP)-conjugated secondary antibody from the EliVision ${ }^{\mathrm{TM}}$ Super kit were purchased from Fuzhou Maixin Biotechnology Development Co., Ltd. (Fuzhou, China). The polyclonal rabbit anti-vascular endothelial growth factor (VEGF; ab46154) antibody was purchased from Abcam (Cambridge, UK). The Total RNA extraction kit (TRIzol) was purchased from BioTeke Corporation (Beijing, China), oligo-(dT) primers and Moloney Murine Leukemia Virus (M-MLV) Reverse Transcriptase were purchased from SunBio Corporation (Dongan-gu, Republic of Korea). The RNase inhibitor was purchased from Takara Biotechnology Co., Ltd. (Dalian, China), and the Polymerase Chain Reaction (PCR) Amplification kit (Taq) was from Sangon Biotech Co., Ltd. (Shanghai, China).

Animal experiment. The rats were housed at $21 \pm 2^{\circ} \mathrm{C}$ at a temperature of $55 \pm 2 \%$ with a $12 \mathrm{~h} / 12 \mathrm{~h}$ light cycle in a specific-pathogen-free laboratory. The rats received standard rat chow and ad libitum access to tap water. The rats were randomly divided into the following groups: The control group $(n=7)$, in which the rats received an injection of $0.1 \mathrm{M}$ acetate buffer; and the diabetes (DM) group ( $n=7)$, in which the rats received a single intraperitoneal (i.p.) injection of streptozotocin (STZ; $65 \mathrm{mg} / \mathrm{kg}$ in $0.1 \mathrm{M}$ acetate buffer; $\mathrm{pH} 4.4$; Sigma-Aldrich, St. Louis, MO, USA), in order to produce a diabetic rat model. A total of $72 \mathrm{~h}$ after the STZ injection, non-fasting blood glucose levels were measured with a portable glucose meter (Optium Xceed; Abbott Laboratories Co., Ltd., Shanghai, China) using whole blood samples obtained from snipped tails, subsequent to anesthesia with $40 \mathrm{mg} / \mathrm{kg}$ intraperitoneal $2 \%$ pentobarbital sodium. The rats were considered diabetic when blood glucose levels reached $16.7 \mathrm{mmol} / \mathrm{l}$. Rats treated with STZ were then intraperitoneally administered the chymase inhibitor $(\mathrm{OPh})_{2}(1 \mathrm{mg} / \mathrm{kg}$ daily), in order to generate the DM + Chy-I group ( $n=10)$. Rats in the control and DM groups were treated with the same volume of saline. The whole experiment lasted 12 weeks. To avoid ketosis and acidosis and improve long-term survival, non-fasting glycaemia was measured once a week, and when serum glucose was greater than $25 \mathrm{mmol} / \mathrm{l}$, rats in the DM and DM + Chy-I groups received $2 \mathrm{U}$ insulin (Humulin NPH; Lilly Suzhou Pharmaceutical Group Co., Ltd., Suzhou, China) subcutaneously. All related animal research was approved by the Ethics Committee of the Peking University First Hospital (Beijing, China).

At the end of the treatment period, all rats were housed individually in metabolic cages for $24 \mathrm{~h}$ for the collection of urine, in order to determine protein and creatinine clearance, which were measured using the Hitachi 7150 Automatic Biochemical Analyzer (Hitachi, Ltd., Tokyo, Japan). Blood pressure was measured when the rats were conscious by the tail cuff method. All rats were sacrificed by cervical dislocation after 12 weeks of $(\mathrm{OPh})_{2}$ treatment under $40 \mathrm{mg} / \mathrm{kg}$ intraperitoneal $2 \%$ pentobarbital sodium anesthesia. Blood samples were obtained from the abdominal aorta, and were used for serum biochemical analyses using the Hitachi 7150 Automatic Biochemical Analyzer. Blood and urine samples were collected into chilled tubes and were stored at $-80^{\circ} \mathrm{C}$ until further use. The left kidney was excised, weighed, and cut into two halves; one half was fixed with $10 \%$ formalin and $2.5 \%$ glutaraldehyde, and the other half was prepared for renal morphological analysis. The right kidney was excised and maintained at $-80^{\circ} \mathrm{C}$ for mRNA extraction.

Immunohistochemical staining. Paraffin-embedded tissue sections ( $3 \mu \mathrm{m}$ for light microscopy; $4 \mu \mathrm{m}$ for immunohistochemistry) were dewaxed with dimethylbenzene (Beijing Yili Fine Chemicals Co., Ltd., Beijing, China), hydrated with ethanol, treated with $5 \% \mathrm{H}_{2} \mathrm{O}_{2}$, and were incubated in a microwave in $0.01 \mathrm{M}$ citrate buffer/pepsin for antigen retrieval for $10 \mathrm{~min}$. Subsequently, the sections were rehydrated in phosphate-buffered saline (PBS) for $15 \mathrm{~min}$, and were blocked with goat serum (AR 0009; Boster Biological Technology Co., Ltd., Pleasanton, CA, USA) at room temperature for $20 \mathrm{~min}$ to reduce nonspecific binding. The sections were then incubated with the following primary antibodies: Mouse monoclonal anti-FN (1:300), mouse monoclonal anti-ColIV (1:300), rabbit polyclonal anti-VEGF (1:200) and mouse monoclonal anti-TGF- $\beta 1$ (1:200), overnight at $4^{\circ} \mathrm{C}$. After rinsing, the sections were incubated with anti-mouse/rabbit HRP-conjugated secondary antibodies from the EliVision ${ }^{\mathrm{TM}}$ Super kit for $30 \mathrm{~min}$ at room temperature, followed by visualization with $0.05 \%$ diaminobenzidine. The negative control sections underwent the same protocol; however, primary antibodies were replaced with PBS. Images of the renal tissue sections were digitally captured and quantitatively assessed using a microscope (Leica DM1000; Leica Microsystems, Wetzlar, Germany) with Leica QWin Pro V2.8 (Leica Microsystems), and computer-assisted image analysis software (Image-Pro Plus software, version 5.02; Media Cybernetics, Inc., Rockville, MD, USA). The sections were coded (allocated a number) by an investigator; however, the images were digitally captured and analyzed by a different investigator who was unaware of the coding. Images of each section were captured using the Leica DM1000 stereomicroscope with a digital camera. The areas positive for the target proteins were automatically calculated by the software, and the affected areas were divided by the total area of microscopic fields. A total of 20 glomeruli were examined for each rat, and the average percentage of positive lesions was obtained for each animal. The tubulointerstitial area did not include the area of the glomeruli.

Reverse transcription PCR (RT-PCR). The mRNA expression levels of FN, ColIV, TGF- $\beta 1$, VEGF and rat mast cell proteinase-1 (RMCP-1) were detected by RT-PCR. $\beta$-actin was used as an internal standard. The expression levels of the target genes were normalized to the levels of $\beta$-actin in each sample. Subsequent to homogenization of the tissues, total RNA was extracted from the frozen renal tissues using an RNA extraction kit. Subsequently, the RNA (5 $\mu \mathrm{g})$ underwent RT to generate cDNA using Superscript II M-MLV reverse transcriptase $(200 \mathrm{U} / \mu \mathrm{l})$, oligo $(\mathrm{dT}) 12-18$ primers $(50 \mu \mathrm{M}$; 
Table I. Comparison of blood pressure and serum biochemical markers between the groups.

\begin{tabular}{lcccccccc}
\hline & $\begin{array}{c}\text { Systolic } \\
\text { pressure } \\
(\mathrm{mmHg})\end{array}$ & $\begin{array}{c}\text { Diastolic } \\
\text { pressure } \\
(\mathrm{mmHg})\end{array}$ & $\begin{array}{c}\text { Blood glucose } \\
(\mathrm{mmol} / \mathrm{l})\end{array}$ & $\begin{array}{c}\text { Total } \\
\text { cholesterol } \\
(\mathrm{mmol} / \mathrm{l})\end{array}$ & $\begin{array}{c}\mathrm{HDL} \\
(\mathrm{mmol} / \mathrm{l})\end{array}$ & $\begin{array}{c}\text { LDL } \\
(\mathrm{mmol} / \mathrm{l})\end{array}$ & $\begin{array}{c}\text { Triglyceride } \\
(\mathrm{mmol} / \mathrm{l})\end{array}$ & $\begin{array}{c}\text { Albumin } \\
(\mathrm{g} / \mathrm{l})\end{array}$ \\
\hline Group & & & & & & & & \\
Control & $123.71 \pm 13.30$ & $100.05 \pm 12.27$ & $8.44 \pm 1.99$ & $1.52 \pm 0.26$ & $1.06 \pm 0.16$ & $0.25 \pm 0.0 .08$ & $0.70 \pm 0.26$ & $38.37 \pm 1.39$ \\
DM & $135.71 \pm 11.16$ & $93.37 \pm 19.95$ & $48.40 \pm 12.13^{\mathrm{a}}$ & $2.31 \pm 0.30^{\mathrm{a}}$ & $1.18 \pm 0.12$ & $0.40 \pm 0.09^{\mathrm{a}}$ & $2.12 \pm 1.28$ & $34.11 \pm 3.00^{\mathrm{a}}$ \\
DM + Chy-I & $136.50 \pm 8.92$ & $99.35 \pm 9.15$ & $40.48 \pm 16.31$ & $1.95 \pm 0.31^{\mathrm{a}, \mathrm{b}}$ & $1.06 \pm 0.23$ & $0.31 \pm 0.10$ & $1.92 \pm 1.66$ & $35.33 \pm 2.83^{\mathrm{a}}$ \\
\hline
\end{tabular}

Data are presented as the mean \pm standard deviation. DM, diabetes; DM + Chy-I, diabetes + chymase inhibitor; HDL, high-density lipoprotein; LDL, low-density lipoprotein. ${ }^{\mathrm{a}} \mathrm{P}<0.05$, vs. the control group; ${ }^{\mathrm{b}} \mathrm{P}<0.05$, vs. the $\mathrm{DM}$ group.

Table II. Comparison of urinary albumin, urinary ACR and KW/BW between the groups.

\begin{tabular}{lccccc}
\hline Group & $\begin{array}{c}\text { Urinary albumin } \\
(\mathrm{mg} / 24 \mathrm{~h})\end{array}$ & $\begin{array}{c}\text { Urinary ACR } \\
(\mathrm{mg} / \mathrm{g})\end{array}$ & $\begin{array}{c}\text { Serum creatinine } \\
(\mu \mathrm{mol} / \mathrm{l})\end{array}$ & $\mathrm{CCr}(\mathrm{ml} / \mathrm{min})$ & $\mathrm{KW} / \mathrm{BW}$ \\
\hline Control & $1.20 \pm 0.97$ & $70.21 \pm 40.30$ & $25.54 \pm 2.33$ & $0.45 \pm 0.36$ & $3.67 \pm 0.40$ \\
DM & $42.57 \pm 43.92^{\mathrm{a}}$ & $1,380.67 \pm 950.44^{\mathrm{a}}$ & $22.39 \pm 3.8$ & $1.32 \pm 1.10^{\mathrm{a}}$ & $8.03 \pm 1.43^{\mathrm{a}}$ \\
DM + Chy-I & $17.88 \pm 12.20$ & $340.34 \pm 150.23^{\mathrm{a}, \mathrm{b}}$ & $23.36 \pm 4.1$ & $1.34 \pm 0.59^{\mathrm{a}}$ & $7.7 \pm 1.321^{\mathrm{a}}$ \\
\hline
\end{tabular}

Data are presented as the mean \pm standard deviation. DM, diabetes; DM + Chy-I, diabetes + chymase inhibitor; ACR, albumin/creatinine ratio; $\mathrm{CCr}$, creatinine clearance; $\mathrm{KW} / \mathrm{BW}$, kidney weight/body weight. ${ }^{\mathrm{a}} \mathrm{P}<0.05$, vs. the control group; ${ }^{\mathrm{b}} \mathrm{P}<0.05$, vs. the $\mathrm{DM}$ group.

$1 \mu \mathrm{l}$; SunBio Corporation) and RNase-free $\mathrm{ddH}_{2} \mathrm{O}(7.5 \mu \mathrm{l})$. The RT reaction was conducted in a mixture containing 5X first-strand M-MLV buffer, $1 \mathrm{mmol} / 1 \mathrm{dNTP}$ and $20 \mathrm{~mol} / 1$ dithiothreitol RNase inhibitor $(40 \mathrm{U} / \mu \mathrm{l})$, at $42^{\circ} \mathrm{C}$ for $50 \mathrm{~min}$. The PCR reaction mixture consisted of $1 \mu \mathrm{l} \mathrm{cDNA}$, $20 \mathrm{pmol} / 1$ primers (SunBio Corporation), $2 \mu 1$ 10X PCR buffer, $0.4 \mathrm{mmol} / \mathrm{l}$ dNTPs, and $2.5 \mathrm{U}$ Taq polymerase. PCR was performed using a Bioer PCR amplification instrument (GeneQ; Hangzhou Bioer Technology Co., Ltd., Hangzhou, China) with the following conditions: Pre-denaturation at $95^{\circ} \mathrm{C}$ for $5 \mathrm{~min}$; followed by 30 cycles of amplification at $95^{\circ} \mathrm{C}$ for $30 \mathrm{sec}$, annealing at $55^{\circ} \mathrm{C}$ for $30 \mathrm{sec}$ and extension at $72^{\circ} \mathrm{C}$ for $30 \mathrm{sec}$; and a final extension step at $72^{\circ} \mathrm{C}$ for $5 \mathrm{~min}$. The PCR primer sequences were as follows: $\beta$-actin, sense 5'-CTG AACCCTAAGGCCAACC-3', antisense 5'-CTG AACCCTAAGGCCAACC-3' (309 bp); FN, sense 5'-CAG TTTGTGGAAGTGACCGA-3', antisense 5'-TGGAGG TTA GTGGGAGCATA-3' (272 bp); ColIV, sense 5'-GTGCGG TTTGTGAAGCACCG-3', antisense 5'-GTTCTTCTC ATG CACACTTC-3' (363 bp); TGF- $\beta 1$, sense 5'-TATAGC AAC AATTCCTGGCG3', antisense 5'-CAGAAG TTGGCATGG TAGCC-3' (446 bp); RMCP-1, sense 5'-GGA CCAGAA CCAAGTGAGA-3', antisense 5'-TTG AAAGTGTTGAAC CAGGA-3' (328 bp); and VEGF, sense 5'-CAATTGAGA CCCTGGTGGACAT-3' and antisense 5'-TTGATCCGCATG ATCTGCATAG-3' (169 bp).

The PCR products were subsequently separated by electrophoresis on $2 \%$ agarose gels, stained with ethidium bromide (Santa Cruz Biotechnology, Inc.) and visualized by ultraviolet (UV) transillumination (Clinx CUV 20 A; Shanghai Clinx Science Instruments Co., Ltd., Shanghai, China). The ratio of the 2 DNA bands (target DNA and $\beta$-actin) densities was measured using a Gel Image Analysis system (AlphaImager; ProteinSimple, San Jose, CA, USA) under UV light.

Statistical analysis. Statistical analyses were performed using SPSS for Windows, version 11.5 (SPSS Inc., Chicago, IL, USA). All values are presented as the mean \pm standard deviation. Comparisons of data between multiple groups were made using one-way analysis of variance, followed by Student-Newman-Keuls. $\mathrm{P}<0.05$ was considered to indicate a statistically significant difference.

\section{Results}

Biochemical analysis. In the present study, the effects of chymase inhibition were investigated on diabetic renal injury in an STZ rat model. Preliminary experiments performed on the STZ-treated rats determined that 12 weeks was the optimal treatment duration for renal pathological analyses. No differences in serum creatinine, blood pressure and triglyceride levels were detected among the control, DM and DM + Chy-I groups. In the DM group, the kidney weight/body weight ratio, blood glucose levels, urinary albumin levels, low-density lipoprotein (LDL) levels and endogenous creatinine clearance rate $(\mathrm{CCr})$ were significantly increased compared with in the control group. However, chymase inhibition had no effect on these factors (Tables I and II). CCr was elevated in the 12-week STZ-treated rats, which is considered a symptom of the glomerular hyperfiltration phase of diabetic nephropathy. The total serum urinary albumin/creatinine ratio (ACR) and cholesterol levels were significantly higher in the DM group compared with in the control group. However, these factors 
A

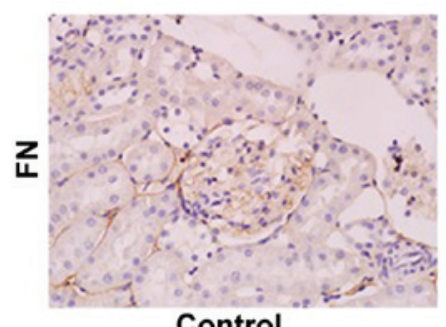

B
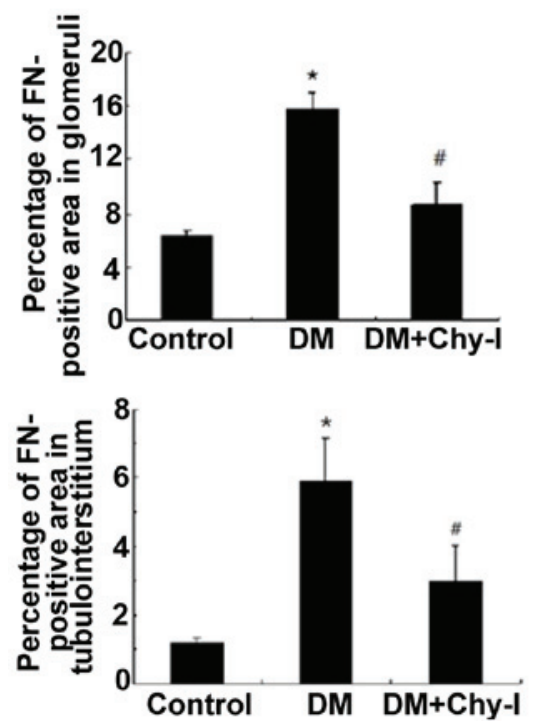

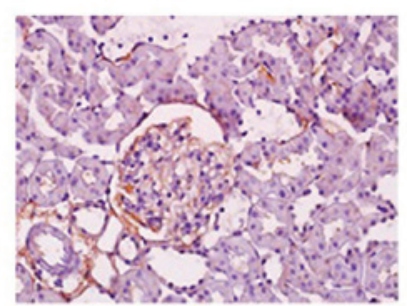

DM

C
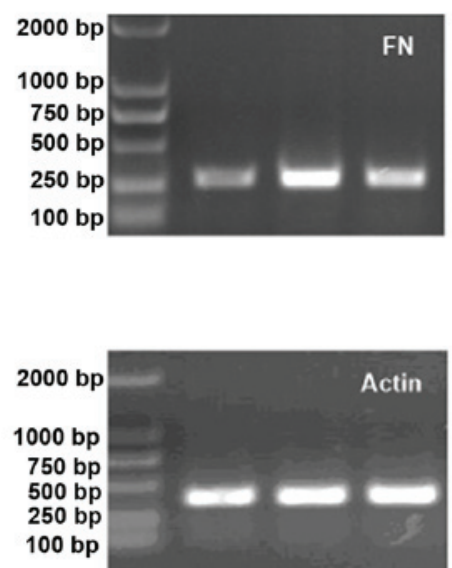

Control DM DM+Chy-I

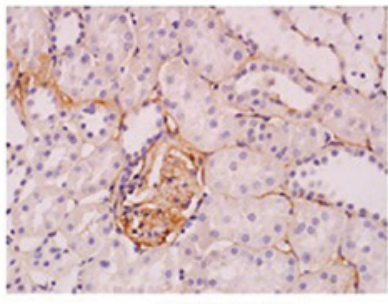

DM+Chy-I

Figure 1. Chymase inhibition decreased the expression of FN in diabetic rat renal tissues. (A) Diabetic kidneys exhibited strong FN immunostaining, which was reduced by treatment with the chymase inhibitor $(\mathrm{OPh})_{2}$ (magnification, $\left.\mathrm{x} 400\right)$. (B) Percentage FN-positive area in the glomeruli and tubulointerstitium of the various groups. Data are presented as the mean \pm standard deviation. ${ }^{*} \mathrm{P}<0.01$, vs. the control group; ${ }^{*} \mathrm{P}<0.01$, vs. the $\mathrm{DM}$ group. (C) Reverse transcription polymerase chain reaction analysis demonstrated that chymase inhibition decreased the expression of FN in diabetic kidneys. Data are presented as the mean \pm standard deviation. ${ }^{*} \mathrm{P}<0.05$, vs. the control group; ${ }^{*} \mathrm{P}<0.05$, vs. the DM group. FN, fibronectin; DM, diabetes group; DM $+\mathrm{Chy}-\mathrm{I}$, diabetes + chymase inhibitor group.

were significantly reduced in the DM + Chy-I group by 84.42 and $24.64 \%$, respectively (Tables I and II).

Effects of chymase inhibition on ECM deposition and RMCP-1 expression. The present study investigated the expression of FN and ColIV, which are two typical markers of diabetic renal injury. Immunohistochemical analysis revealed that the protein expression of FN was significantly increased in glomeruli and at the renal tubulointerstitium in diabetic rats, as compared with in the control rats 2.49 -fold increase in glomeruli and 4.98-fold increase in tubulointerstitium). However, in the $\mathrm{DM}+$ Chy-I group, the intensity of FN staining was markedly decreased in these regions (by $55.15 \%$ in glomeruli and $50.59 \%$ in tubulointerstitium) (Fig. 1A and B). RT-PCR was also performed to detect FN gene expression in the various groups (Fig. 1C). Compared with in the normal control group, FN expression exhibited a 2.45-fold increase in the DM group, whereas chymase inhibition reduced FN expression by $25.35 \%$. These results indicate that chymase inhibition may limit the expression of ECM components.

The previously discussed findings were confirmed by detection of the renal expression of another main component of the ECM, ColIV. In the DM group, ColIV was localized in the same regions as in the control group; however, its expression was significantly increased (5.23-fold increase in the glomerular mesangial area and 3.00-fold increase in tubulointerstitium). Treatment with a chymase inhibitor decreased the staining intensity of ColIV (to $37.75 \%$ in the glomerular mesangial area and to $65.27 \%$ in tubulointerstitium) (Fig. 2A and B). RT-PCR analysis revealed that the expression levels of ColIV were increased in the diabetic rat renal tissues by 1.61-fold compared with in the control group, whereas chymase inhibition downregulated the expression of ColIV by $17.24 \%$ (Fig. 2C). Quantitative analysis confirmed that chymase inhibition reversed the deposition of ECM components.

The expression levels of RMCP-1 were significantly higher in the diabetic renal tissues compared with in the normal renal tissues, as revealed by RT-PCR $(0.288 \pm 0.026$ vs. $0.709 \pm 0.054$; $\mathrm{P}<0.01)$. Furthermore, treatment with a chymase inhibitor reduced the expression levels of RMCP-1 (Fig. 3).

Effects of chymase inhibition on the expression of VEGF. The expression of VEGF was concentrated in renal tubules. While, in normal glomeruli, VEGF was expressed sporadically in epithelial cells. Immunostaining revealed increased expression of VEGF protein in the kidneys of the DM group compared with in the control group (10.52-fold increase in glomeruli and 4.03-fold increase in tubules). However, this overexpression was inhibited following treatment with the chymase inhibitor $(\mathrm{OPh})_{2}$ (to $63.65 \%$ in glomeruli and to $38.35 \%$ in tubules) (Fig. 4A and B). In addition, in the DM group, the mRNA 
A

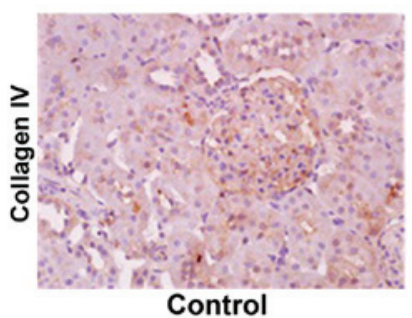

B
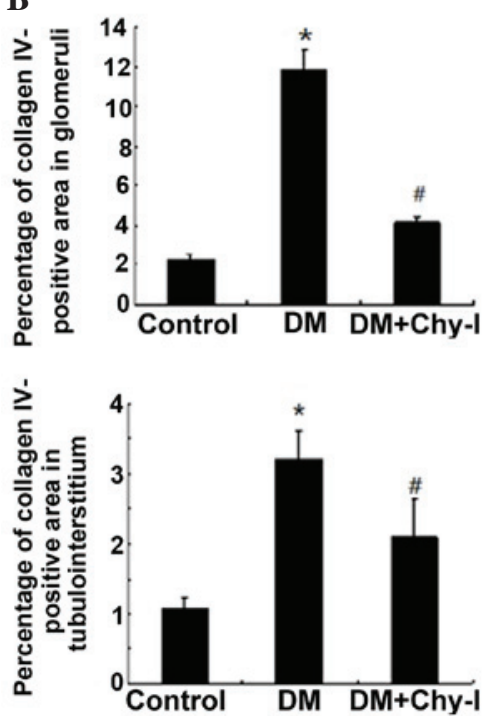

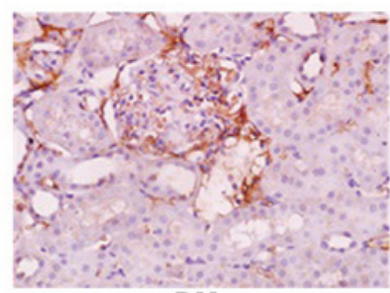

DM

C

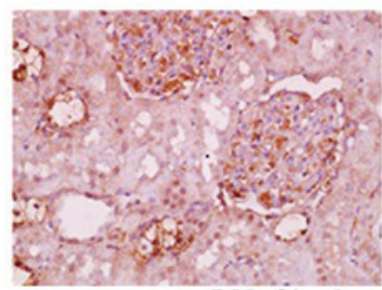

DM+Chy-I
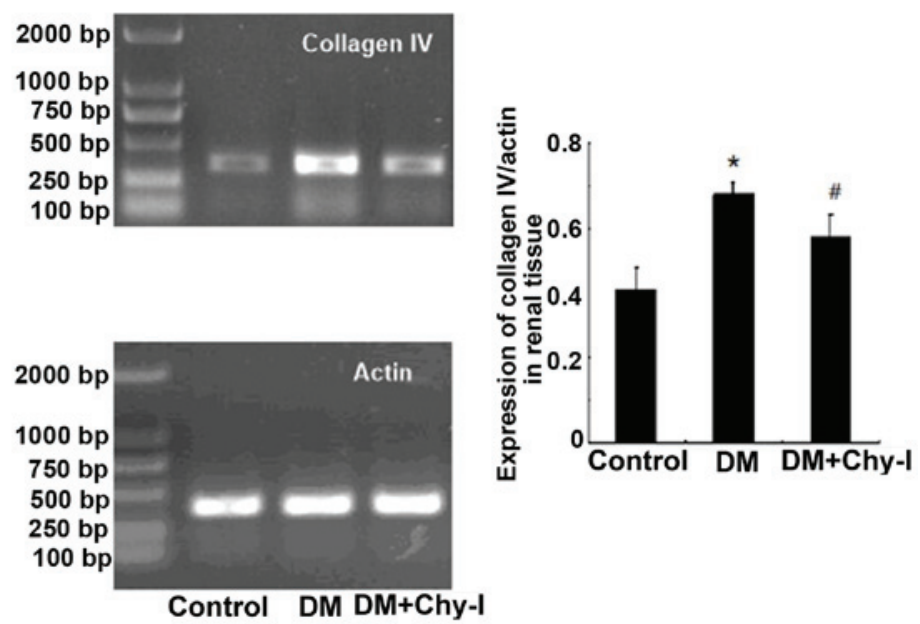

Figure 2. Chymase inhibition decreased the expression of ColIV in diabetic rat renal tissues. (A) Diabetic kidneys exhibited increased ColIV immunostaining, which was reduced by treatment with the chymase inhibitor $(\mathrm{OPh})_{2}$ (magnification, $\left.\mathrm{x} 400\right)$. (B) Percentage ColIV-positive area in the glomeruli and tubulointerstitium of the various groups. Data are presented as the mean \pm standard deviation. ${ }^{*} \mathrm{P}<0.01$, vs. the control group; ${ }^{*} \mathrm{P}<0.01$, vs. the $\mathrm{DM}$ group. (C) Reverse transcription polymerase chain reaction analysis demonstrated that chymase inhibition decreased the expression of ColIV in diabetic kidneys. Data are presented as the mean \pm standard deviation. ${ }^{*} \mathrm{P}<0.05$, vs. the control group; ${ }^{~} \mathrm{P}<0.05$, vs. the DM group. ColIV, collagen type IV; DM, diabetes group; DM + Chy-I, diabetes + chymase inhibitor group.
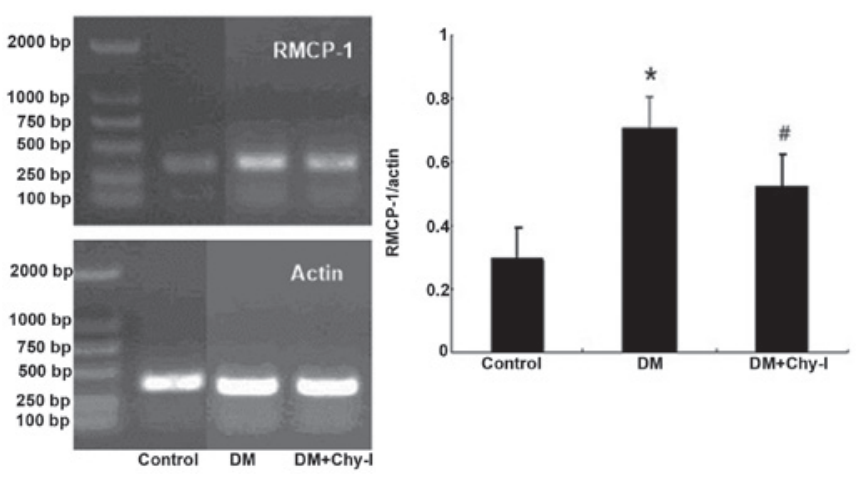

Figure 3. Chymase inhibition decreased the expression of RMCP-1 in diabetic rat renal tissues. Reverse transcription polymerase chain analysis demonstrated that chymase inhibition decreased the expression of RMCP-1 in diabetic kidneys. Data are presented as the mean \pm standard deviation. ${ }^{*} \mathrm{P}<0.01$, vs. the control group; ${ }^{\prime \prime} \mathrm{P}<0.05$, vs. the $\mathrm{DM}$ group. RMCP- 1 , rat mast cell proteinase-1; DM, diabetes group; DM + Chy-I, diabetes + chymase inhibitor group.

expression levels of VEGF were significantly increased by 2.33 -fold compared with in the control group. Treatment with the chymase inhibitor $(\mathrm{OPh})_{2}$ reversed the increases in VEGF mRNA expression (Fig. 4C).

Effects of chymase inhibition on the expression of TGF- $\beta 1$. Immunohistochemical analysis revealed that TGF- $\beta 1$ was upregulated in the glomerular mesangium and tubular cells of the diabetic rats (2.69-fold increase in glomeruli and 1.51-fold increase in tubulointerstitium) (Fig. 5A and B). Conversely, chymase inhibition reversed the overexpression of TGF- $\beta 1$ in diabetic rats (to $73.43 \%$ in glomeruli and to $81.36 \%$ in tubulointerstitium). RT-PCR analysis revealed that the renal tissues from the DM group exhibited increased TGF- $\beta 1 \mathrm{mRNA}$ expression, as compared with the control rats $(82.22 \pm 11.35$ vs. $124.15 \pm 4.32 ; \mathrm{P}<0.05$ ), whereas chymase inhibition reduced the expression of TGF- $\beta 1$ in diabetic renal tissues $(124.15 \pm 4.32$ vs. 103.07士 6.30; $\mathrm{P}<0.05$ ) (Fig. 5C).

\section{Discussion}

The present study established an in vivo model to explore the potential preventive effects of the chymase inhibitor $(\mathrm{OPh})_{2}$ on renal lesions in diabetic rats. In a previous study, almost all renal mast cells in patients with diabetic nephropathy were shown to produce chymase (9). The present study determined the expression of chymase in rat renal tissues. The expression levels of the chymase encoding gene, RMCP-1, were markedly enhanced in diabetic kidneys. A previous study demonstrated that the mRNA expression levels of chymase were upregulated in glucose-stimulated mesangial cells (10). Mast cells are thought to be the main source of chymase; however, the present study failed to identify abundant mast cells in renal tissues by toluidine blue staining (data not shown). This result 
A

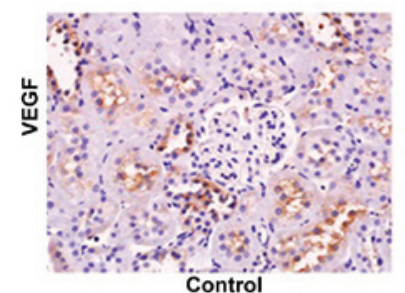

B
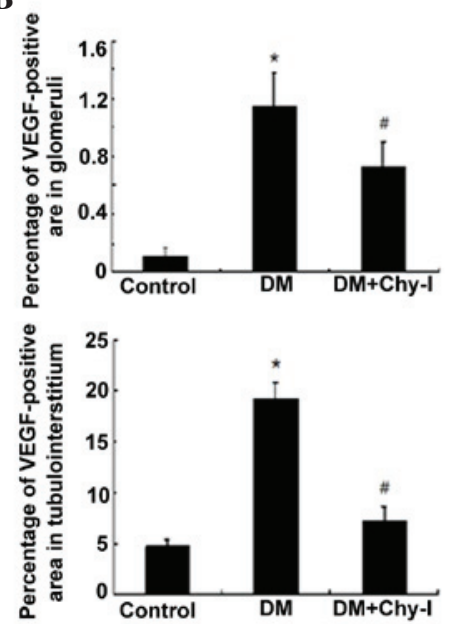

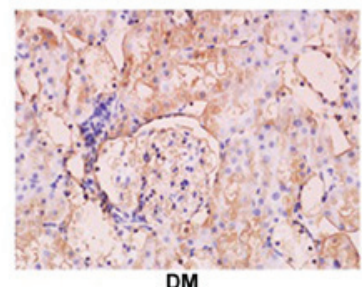

C

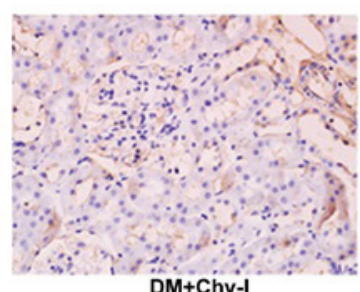

DM+Chy-1
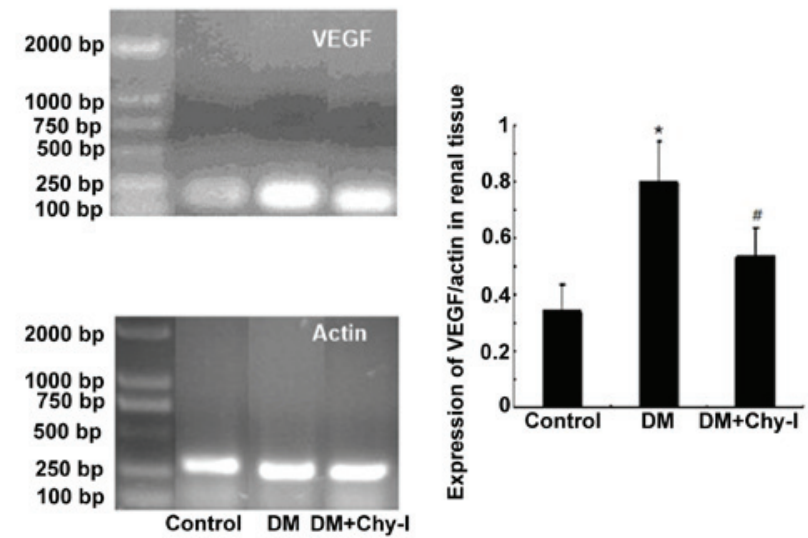

Figure 4. Chymase inhibition downregulated the expression of VEGF in diabetic rat renal tissues. (A) Diabetic kidneys exhibited increased VEGF immunostaining, which was reduced by treatment with the chymase inhibitor $(\mathrm{OPh})_{2}$ (magnification, $\left.\mathrm{x} 400\right)$. (B) Percentage VEGF-positive area in the glomeruli and tubulointerstitium of the various groups. Data are presented as the mean \pm standard deviation. ${ }^{*} \mathrm{P}<0.01$, vs. the control group; ${ }^{*} \mathrm{P}<0.01$, vs. the $\mathrm{DM}$ group. (C) Chymase inhibition downregulated the expression of VEGF, as detected by reverse transcription polymerase chain reaction. Data are presented as the mean \pm standard deviation. ${ }^{~} \mathrm{P}<0.01$, vs. the control group; ${ }^{~} \mathrm{P}<0.01$, vs. the DM group. VEGF, vascular endothelial growth factor; DM, diabetes group; DM + Chy-I, diabetes + chymase inhibitor group.

A

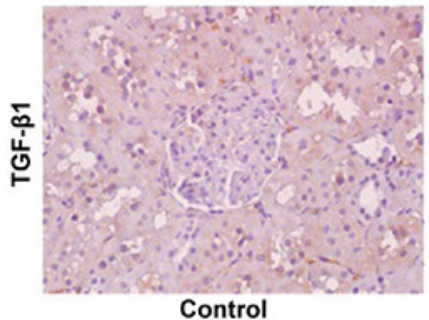

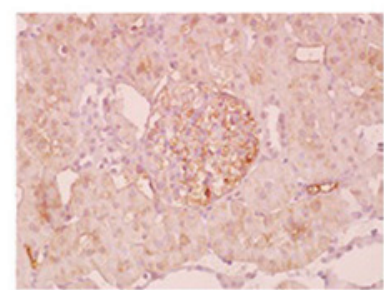

DM

C

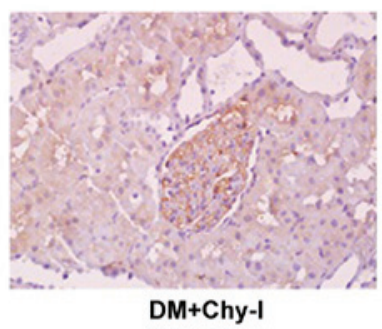

DM+Chy-1
B
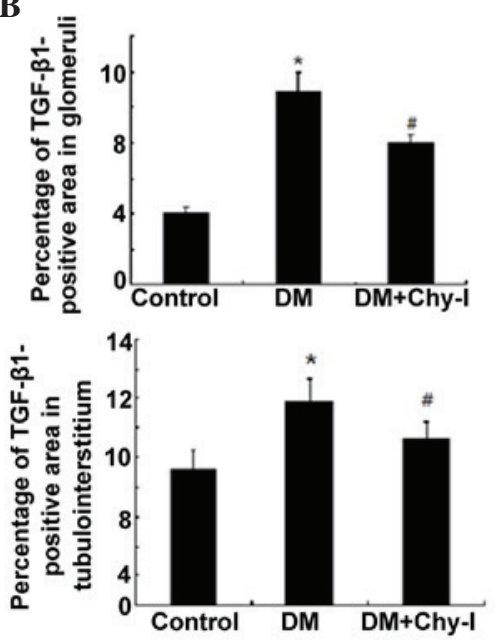
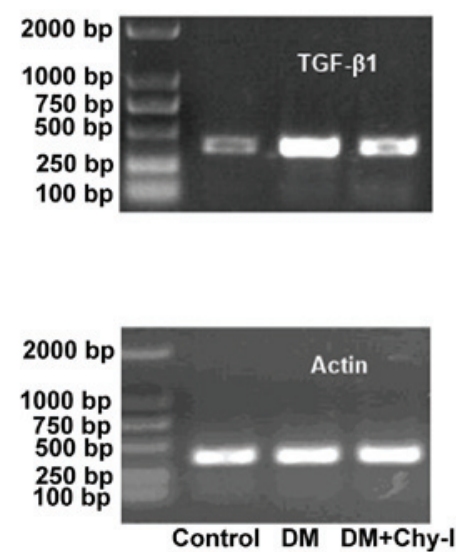

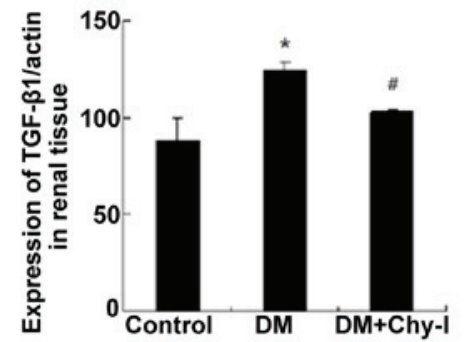

Figure 5. Chymase inhibition decreased the expression of TGF- $\beta 1$ in diabetic rat renal tissues. (A) Diabetic kidneys exhibited strong TGF- $\beta 1$ immunostaining, which was reduced following treatment with the chymase inhibitor $(\mathrm{OPh})_{2}$ (magnification, $\left.\mathrm{x} 400\right)$. (B) Percentage TGF- $\beta 1$-positive area in the glomeruli and tubulointerstitium of the various groups. Data are presented as the mean \pm standard deviation. ${ }^{*} \mathrm{P}<0.01$, vs. the control group; ${ }^{*} \mathrm{P}<0.01$, vs. the $\mathrm{DM}$ group. (C) Reverse transcription polymerase chain analysis demonstrated that chymase inhibition decreased TGF- $\beta 1$ expression in diabetic kidneys. Data are presented as the mean \pm standard deviation. "P $<0.05$, vs. the control group; " $\mathrm{P}<0.05$, vs. the DM group. TGF- $\beta 1$, transforming growth factor- $\beta 1$; DM, diabetes group; DM + Chy-I, diabetes + chymase inhibitor group. 
is consistent with the findings of a previous study, in which Cristovam et al (10) demonstrated that mast cells were absent in both control and diabetic kidneys, thus suggesting that chymase is synthesized by resident renal cells.

Disordered lipid metabolism is a common feature of diabetes mellitus. In the present study, the chymase inhibitor $(\mathrm{OPh})_{2}$ lowered cholesterol levels in diabetic rats via an unknown mechanism. Consistent with these findings, it has been previously reported that arterial chymase is activated when cholesterol levels are elevated in animals fed a high-lipid diet (11). Mast cell chymase actively degrades high-density lipoprotein and thus generates defective particles that are unable to initiate cholesterol efflux from the arterial wall (12).

The majority of patients with diabetic nephropathy develop hypertension, alongside proteinuria. In the present study, no obvious differences were observed in blood pressure between the rat groups. $(\mathrm{OPh})_{2}$ lowered urinary ACR in diabetic rats but did not affect blood pressure or blood glucose levels, thus indicating that this chymase inhibitor exerts its effects on renal lesions independent of hypertension and hyperglycemia.

FN and ColIV are the main components of the ECM. ECM deposition occurs in the early stage of renal disease. An indication of ECM overaccumulation is abnormally increased FN levels, which is a main feature of glomerular sclerosis and interstitial fibrosis. In addition, an imbalance between ColIV synthesis and degradation directly affects ECM deposition, and abnormally high levels of ColIV in patients with renal disease have been closely associated with the severity of diabetic nephropathy (13).

In vitro, rat and human chymases have been reported to degrade FN, which has an important role in the attachment of cultured vascular smooth muscle cells (14). Conversely, chymase inhibition has been reported to downregulate the expression of FN and ColIV in animal models of ischemia and fibrosis $(15,16)$. These results, together with the findings of the present study, suggested that chymase may participate in ECM deposition in diabetes-induced renal fibrosis, and that chymase inhibition could attenuate the progression of diabetic nephropathy. These findings may also explain the reduction in urinary protein secretion induced by chymase inhibition.

VEGF has important roles in blood vessel growth, endothelial survival and microvasculature maintenance. VEGF is abundantly expressed in glomerular epithelial cells, also known as podocytes, and tubular epithelial cells, whereas the glomerular and peritubular capillary endothelial cells express VEGF receptors (17). VEGF renal expression is decreased in several animal models of kidney disease, and VEGF administration is protective (18). However, plasma VEGF levels in patients with diabetic nephropathy are increased, and suppressing VEGF has been shown to improve diabetic nephropathy in animal models (19-22). In diabetic models, VEGF secretion and the expression of its receptors are increased by high glucose concentrations in the kidneys (23). In addition, patients with diabetes and overt proteinuria express higher levels of VEGF, and excretion of urinary VEGF is increased in those with a higher degree of proteinuria (24). In the present study, diabetic rats exhibited higher urinary ACR and increased VEGF expression in renal tissues, which is consistent with the findings of previous animal studies and clinical observations $(23,24)$. Chymase inhibition reduced urinary protein excretion and the mRNA expression levels of VEGF in diabetic rats, thus suggesting that the chymase inhibitor may decrease urinary protein excretion and renal lesions via its inhibition of VEGF. It has previously been reported that the chymase-Ang II-VEGF pathway may operate in granulation tissues as the primary mediator of angiogenesis (25). However, the results of the present study did not indicate the involvement of this pathway in VEGF regulation of chymase. Chymase may induce VEGF via the VEGF paracrine loop in glomeruli, as reported previously in podocyte-specific VEGF-deficient mice (26). VEGF itself stimulates collagen and FN expression in mesangial cells and, in turn, enhances TGF- $\beta 1$-induced ECM accumulation (27). TGF- $\beta 1$ and VEGF interact with each other, and increased secretion of VEGF, induced by TGF- $\beta 1$, may be a possible explanation for the role of TGF- $\beta 1$ in the development of albuminuria (28).

Chymase strongly promotes accumulation of inflammatory cells, and also converts TGF- $\beta$ and matrix metalloproteinase- 9 precursors to their active forms. These multiple functions of chymase may have an important role in the development and promotion of various types of disease (29). TGF- $\beta 1$ is a critical cytokine in cell proliferation, ECM deposition and fibrosis. It stimulates glomerular mesangial cells and tubular epithelial cells, and enhances the expression of ColI, III, IV and other non-collagen glycoproteins $(30,31)$. In the present study, chymase inhibition depressed the upregulation of TGF- $\beta 1$ in diabetic rats, alongside urinary albumin secretion. These results indicated that TGF- $\beta 1$ may have an important role in chymase-induced renal damage. It has previously been reported that chymase converts the TGF- $\beta 1$ precursor to its active form (15). Autocrine TGF- $\beta 1$ may also have a critical role in the growth and basal ColIV production of renal tubular epithelial cells $(14,32)$. Increased levels of TGF- $\beta 1$ have been observed in both clinical and experimental models of diabetes, and the deleterious effects of high glucose levels are attributed primarily to the autocrine action of TGF- $\beta 1$ (33). Autocrine TGF- $\beta 1$ signaling in proliferating proximal tubule cells usually exceeds the levels that are necessary for physiological regeneration (34), thus indicating that chymase inhibition may downregulate TGF- $\beta 1$ expression by depressing its activation, as shown in the present study.

In conclusion, the results of the present study indicated that chymase may participate in diabetic renal fibrosis by inducing excessive ECM deposition, probably via its regulation of TGF- $\beta 1$ and VEGF. The chymase inhibitor $(\mathrm{OPh})_{2}$ reversed the effects of chymase as a fibrogenic factor by restraining the expression of TGF- $\beta 1$ and VEGF. In addition, chymase inhibition resulted in a reduced urinary ACR and alleviated diabetic renal fibrosis. These results indicated the potential of chymase inhibitors for the treatment of diabetic nephropathy; however, the mechanisms underlying the regulation of VEGF and TGF- $\beta 1$ by chymase require further investigation.

\section{Acknowledgements}

The present study was supported by the Basic Clinical Cooperation Foundation of Capital Medical University (grant no. 11JL41). 


\section{References}

1. Huang XR, Chen WY, Truong LD and Lan HY: Chymase is upregulated in diabetic nephropathy: Implications for an alternative pathway of angiotensin II-mediated diabetic renal and vascular disease. J Am Soc Nephrol 14: 1738-1747, 2003.

2. Fan YY, Nishiyama A, Fujisawa Y, Kobori H, Nakano D, Matsuura J, Hase N, Hitomi H, Kiyomoto H, Urata H and Kohno M: Contribution of chymase-dependent angiotensin II formation to the progression of tubulointerstitial fibrosis in obstructed kidneys in hamsters. J Pharmacol Sci 111: 82-90, 2009.

3. Urata H, Kinoshita A, Misono KS, Bumpus FM and Husain A: Identification of a highly specific chymase as the major angiotensin II-forming enzyme in the human heart. J Biol Chem 265: 22348-22357, 1990.

4. Miyazaki M and Takai S: Tissue angiotensin II generating system by angiotensin-converting enzyme and chymase. J Pharmacol Sci 100: 391-397, 2006

5. Takai S, Sakonjo H, Fukuda K, Jin D, Sakaguchi M, Kamoshita K, Ishida K, Sukenaga Y and Miyazaki M: A novel chymase inhibitor, 2-(5-formylamino-6-oxo-2-phenyl-1,6-dihydropyrimidine-1-yl)-N-[[,4-dioxo-1-phenyl-7-(2-pyridyloxy)] 2-heptyl]acetamide (NK3201), suppressed intimal hyperplasia after balloon injury. J Pharmacol Exp Ther 304: 841-844, 2003

6. Okamoto Y, Takai S and Miyazaki M: Effect of chymase-dependent transforming growth factor beta on peritoneal adhesion formation in a rat model. Surg Today 34 865-867, 2004

7. Oleksyszyn J and Powers JC: Irreversible inhibition of serine proteases by peptide derivatives of (alpha-aminoalkyl) phosphonate diphenyl esters. Biochemistry 30: 485-493, 1991

8. Takai S, Yuda A, Jin D, Nishimoto M, Sakagichi M, Sasaki S and Miyazaki M: Inhibition of chymase reduces vascular proliferation in dog grafted veins. FEBS Lett 467: 141-144, 2000

9. Ninichuk V, Khandoga AG, Segerer S, Loetscher P, Schlapbach A, Revesz L, Feifel R, Khandoga A, Krombach F, Nelson PJ, et al The role of interstitial macrophages in nephropathy of type 2 diabetic db/db mice. Am J Pathol 170: 1267-1276, 2007.

10. Cristovam PC, Carmona AK, Arnoni CP, Maquigussa E, Pereira LG and Boim MA: Role of chymase in diabetic nephrology. Exp Biol Med (Maywood) 237: 985-992, 2012.

11. Uehara Y, Urata H, Ideishi M, Arakawa K and Saku K: Chymase inhibition suppresses high-cholesterol diet-induced lipid accumulation in the hamster aorta. Cardiovasc Res 55: 870-876, 2002.

12. Kovanen PT: Mast cells: Multipotent local effector cells in atherothrombosis. Immunol Rev 217: 105-122, 2007.

13. Ruiz-Torres MP, López-Ongil S, Griera M, Díez-Marqués ML, Rodríguez-Puyol M and Rodríguez-Puyol D: The accumulation of extracellular matrix in the kidney: Consequences on cellular function. J Nephrol 18: 334-340, 2005.

14. Leskinen MJ, Lindstedt KA, Wang Y and Kovanen PT: Mast cell chymase induces smooth muscle cell apoptosis by a mechanism involving fibronectin degradation and disruption of focal adhesions. Arterioscler Thromb Vasc Biol 23: 238-243, 2003.

15. Kanemitsu H, Takai S, Tsuneyoshi H, Nishina T, Yoshikawa K, Miyazaki M, Ikeda T and Komeda M: Chymase inhibition prevents cardiac fibrosis and dysfunction after myocardial infarction in rats. Hypertens Res 29: 57-64, 2006.

16. Maeda Y, Inoguchi T, Takei R, Sawada F, Sasaki S, Fujii M, Kobayashi K, Urata H, Nishiyama A and Takayanagi R: Inhibition of chymase protects against diabetes-induced oxidative stress and renal dysfunction in hamsters. Am J Physiol Renal Physiol 299: F1328-F1338, 2010

17. Simon M, Röckl W, Hornig C, Gröne EF, Theis H, Weich HA, Fuchs E, Yayon A and Gröne HJ: Receptors of vascular endothelial growth factor/vascular permeability factor (VEGF/VPF) in fetal and adult human kidney: Localization and [125I]VEGF binding sites. J Am Soc Nephrol 9: 1032-1044, 1998.
18. Kang DH, Joly AH, Oh SW, Hugo C, Kerjaschki D, Gordon KL, Mazzali M, Jefferson JA, Hughes J, Madsen KM, et al: Impaired angiogenesis in the remnant kidney model: I. Potential role of vascular endothelial growth factor and thrombospondin-1. J Am Soc Nephrol 12: 1434-1447, 2001.

19. Tsuchida K, Makita Z, Yamagishi S, Atsumi T, Miyoshi H, Obara S, Ishida M, Ishikawa S, Yasumura K and Koike T: Suppression of transforming growth factor beta and vascular endothelial growth factor in diabetic nephropathy in rats by a novel advanced glycation end product inhibitor, OPB-9195. Diabetologia 42: 579-588, 1999.

20. Cha DR, Kim NH, Yoon JW, Jo SK, Cho WY, Kim HK and Won NH: Role of vascular endothelial growth factor in diabetic nephropathy. Kidney Int Suppl 77: S104-S112, 2000.

21. de Vriese AS, Tilton RG, Elger M, Stephan CC, Kriz W and Lameire NH: Antibodies against vascular endothelial growth factor improve early renal dysfunction in experimental diabetes. J Am Soc Nephrol 12: 993-1000, 2001.

22. Schrijvers BF, Flyvbjerg A, Tilton RG, Lameire NH and De Vriese AS: A neutralizing VEGF antibody prevents glomerular hypertrophy in a model of obese type 2 diabetes, the Zucker diabetic fatty rat. Nephrol Dial Transplant 21: 324-329, 2006.

23. Cooper ME, Vranes D, Youssef S, Stacker SA, Cox AJ, Rizkalla B, Casley DJ, Bach LA, Kelly DJ and Gilbert RE: Increased renal expression of vascular endothelial growth factor (VEGF) and its receptor VEGFR-2 in experimental diabetes. Diabetes 48: 2229-2239, 1999.

24. Hovind P, Tarnow L, Oestergaard PB and Parving HH: Elevated vascular endothelial growth factor in type 1 diabetic patients with diabetic nephropathy. Kidney Int Suppl 75: S56-S61, 2000.

25. Katada J, Muramatsu M, Hayashi I, Tsutsumi M, Konishi Y and Majima M: Significance of vascular endothelial cell growth factor up-regulation mediated via a chymase-angiotensin-dependent pathway during angiogenesis in hamster sponge granulomas. J Pharmacol Exp Ther 302: 949-956, 2002.

26. Eremina V, Sood M, Haigh J, Nagy A, Lajoie G, Ferrara N, Gerber HP, Kikkawa Y, Miner JH and Quaggin SE: Glomerular-specific alterations of VEGF-A expression lead to distinct congenital and acquired renal diseases. J Clin Invest 111: 707-716, 2003

27. Wang L, Kwak JH, Kim SI, He Y and Choi ME: Transforming growth factor-beta1 stimulates vascular endothelial growth factor 164 via mitogen-activated protein kinase kinase 3-p38alpha and p38delta mitogen-activated protein kinase-dependent pathway in murine mesangial cells. J Biol Chem 279: 33213-33219, 2004

28. Li X, Hu J, Zhang Q, Sun X and Li S: Urocortin 1 improves renal function in rats with streptozotocin-induced diabetes by inhibiting overproduction of TGF-beta 1 and VEGF. Br J Pharmacol 157: 994-1003, 2009.

29. Takai S, Jin D and Miyazaki M: Multiple mechanisms for the action of chymase inhibitors. J Pharmacol Sci 118: 311-316, 2012

30. Khera TK, Martin J, Riley SG, Steadman R and Phillips AO: Glucose modulates handling of apoptotic cells by mesangial cells: Involvement of TGF-beta1. Lab Invest 87: 690-701, 2007.

31. Umezono T, Toyoda M, Kato M, Miyauchi M, Kimura M, Maruyama M, Honma M, Yagame M and Suzuki D: Glomerular expression of CTGF, TGF-beta 1 and type IV collagen in diabetic nephropathy. J Nephrol 19: 751-757, 2006.

32. Grande JP, Warner GM, Walker HJ, Yusufi AN, Cheng J, Gray CE, Kopp JB and Nath KA: TGF-betal is an autocrine mediator of renal tubular epithelial cell growth and collagen IV production. Exp Biol Med (Maywood) 227: 171-181, 2002.

33. Shankland SJ, Scholey JW, Ly H and Thai K: Expression of transforming growth factor-beta 1 during diabetic renal hypertrophy. Kidney Int 46: 430-442, 1994.

34. Geng H, Lan R, Wang G, Siddiqi AR, Naski MC, Brooks AI, Barnes JL, Saikumar P, Weinberg JM and Venkatachalam MA: Inhibition of autoregulated TGF-beta signaling simultaneously enhances proliferation and differentiation of kidney epithelium and promotes repair following renal ischemia. Am J Pathol 174: 1291-1308, 2009 